\title{
Aftershock activity of the 2015 Gorkha, Nepal, earthquake determined using the Kathmandu strong motion seismographic array
}

\author{
Masayoshi Ichiyanagi ${ }^{1 *}$, Nobuo Takai ${ }^{2}$, Michiko Shigefuji ${ }^{1}$, Subeg Bijukchhen ${ }^{3}$, Tsutomu Sasatani ${ }^{4}$, Sudhir Rajaure ${ }^{5}$, \\ Megh Raj Dhital ${ }^{6}$ and Hiroaki Takahashi ${ }^{1}$
}

\begin{abstract}
The characteristics of aftershock activity of the 2015 Gorkha, Nepal, earthquake (Mw 7.8) were evaluated. The mainshock and aftershocks were recorded continuously by the international Kathmandu strong motion seismographic array operated by Hokkaido University and Tribhuvan University. Full waveform data without saturation for all events enabled us to clarify aftershock locations and decay characteristics. The aftershock distribution was determined using the estimated local velocity structure. The hypocenter distribution in the Kathmandu metropolitan region was well determined and indicated earthquakes located shallower than $12 \mathrm{~km}$ depth, suggesting that aftershocks occurred at depths shallower than the Himalayan main thrust fault. Although numerical investigation suggested less resolution for the depth component, the regional aftershock epicentral distribution of the entire focal region clearly indicated earthquakes concentrated in the eastern margin of the major slip region of the mainshock. The calculated modified Omori law's $p$ value of 1.35 suggests rapid aftershock decay and a possible high temperature structure in the aftershock region.
\end{abstract}

Keywords: 2015 Gorkha Nepal earthquake, Aftershock activity, Local seismographic array

\section{Introduction}

On April 25, 2015, a large shallow earthquake (Mw 7.8) occurred in the Gorkha region of central Nepal. Strong seismic waves triggered a destructive disaster in this region, including the capital city, Kathmandu. Shallow-dipping focal mechanisms and a depth of $15 \mathrm{~km}$ from US Geological Survey National Earthquake Information Center (USGS-NEIC) suggest that this event may have occurred on the main thrust belt of the Indian and Eurasian collision system. Historical seismicity and recent geodetic surveys had clearly pointed out a seismic gap in the focal region, and a high earthquake risk had been recognized (Bilham et al. 1997; Bilham and Ambraseys 2005).

Hokkaido University of Japan and Tribhuvan University of Nepal have operated a strong motion seismographic

\footnotetext{
* Correspondence: ichimasa@mail.sci.hokudai.ac.jp

${ }^{1}$ Institute of Seismology and Volcanology, Hokkaido University, Kita 10, Nishi 8,

Kita-ku, Sapporo, Japan

Full list of author information is available at the end of the article
}

array along an east-west line in the Kathmandu metropolitan area with four seismographs since 2011 (Takai et al. 2016). This array was designed to collect continuous waveform data in order to evaluate strong motion forecasting of the anticipated destructive earthquakes. Our observation system fully recorded the mainshock and aftershock sequence of this earthquake. In this study, we present the characteristics of the aftershock activity using original data from the local seismographic array.

\section{Data and analysis}

The Kathmandu strong motion seismographic array was initiated with four stations along an east-west alignment in the city (Fig. 1a). A portable accelerometer type strong motion seismograph (Mitsutoyo JEP6A3-2) was installed with a 24-bit AD data logger with a $100-\mathrm{Hz}$ sampling rate. The frequency range of this system was 0.1-50 Hz. Time calibration was performed using GPS signals with an accuracy of $0.01 \mathrm{~s}$. This system was

\section{Springer}



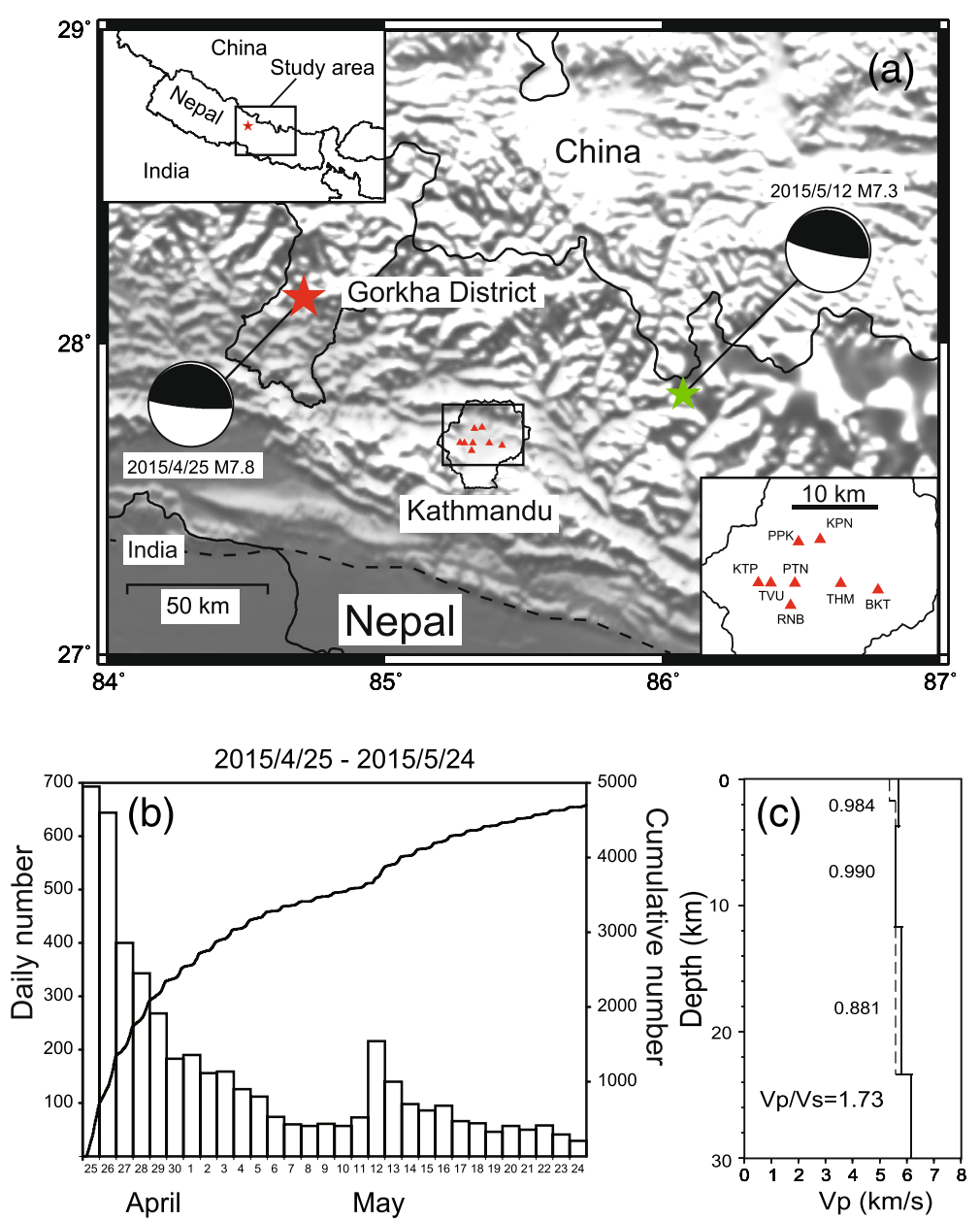

Fig. 1 a Map of focal region with epicenters of the mainshock (red star) and largest aftershock (green star), their focal mechanisms from USGSNEIC, and seismographic stations (red triangles). Dashed line indicates the main Himalayan thrust belt from Lave and Avouac (2000). The seismographic array is located in the northern part of the Himalayan main thrust fault. $\mathbf{b}$ Number of daily and cumulative aftershocks for one month from the mainshock. No magnitude cutoff was operated. Increased number on May 12, 2015 was due to the largest aftershock. c One-dimensional P-wave velocity structure beneath the Kathmandu seismographic array estimated from this study is shown by solid line. Values of resolution matrix for each layer are also shown. Dashed line and data for depths greater than $24 \mathrm{~km}$ are from Monsalve et al. (2006)

operated using a lead battery. Data were recorded in 16GB memory card. On May 5, 2015, 10 days after the mainshock, four sites were added along a north-south transect to investigate aftershock activity. A total of eight stations had been operated since May 5, 2015.

Waveform data from April 25 to May 24, 2015 were analyzed. P- and S-wave arrival phases at each station were picked by an operator with homogeneous criteria using the WIN system (Urabe and Tsukada 1991). Our seismographic array continuously recorded the mainshock and aftershocks during this period without missing any data. Although the mainshock and several strong aftershocks generated large accelerations, the strong motion sensor with a wide dynamic range logger enabled us to record full waveforms without any saturation. These observational conditions allowed us to easily read the P- and
S-phases of all the detected earthquake events. Integrated velocity waveform data were used. An event meeting the criterion of more than three simultaneous P-phases and one S-phase was determined as an earthquake. Magnitude calculation was carried out using the maximum amplitude and hypocenter distance (Watanabe 1971). A total of 4780 earthquakes were evaluated from April 25 to May 24, 2015 (Fig. 1b). Hereafter, we only used data from after May 5, 2015 for hypocenter estimation because there were fewer stations before then. The properties of aftershock number decay, however, were evaluated using all data after the mainshock occurrence.

In order to reduce the hypocenter error, the local P-wave one-dimensional velocity structure in the Kathmandu region was evaluated. A total of 237 earthquakes occurring near the seismographic array were selected for estimation. 
A trial-and-error iteration procedure with an a priori structure (Monsalve et al. 2006) using Crosson's (1976) scheme was carried out. The convergence criterion for travel time residuals was set to $0.001 \mathrm{~s}$. The values of the resolution matrix shown in Fig. 1c indicate that the estimated structure explains the observed travel times quite well. Our results are consistent with those of Monsalve et al. (2006), suggesting an approximately invariant velocity value for the upper crust. The velocity structure from Monsalve et al. (2006) was applied to depths greater than $24 \mathrm{~km}$ because of coarser resolution in our velocity estimation.

Hypocenter determination using the above onedimensional velocity model with $\mathrm{Vp} / \mathrm{Vs}=1.73$ was conducted (Mahesh et al. 2013). First, we evaluated the hypocenters of earthquakes occurring near the array. We were able to apply a conventional double-difference procedure (Waldhauser and Ellsworth 2000) because the hypocenters were close to the array. A total of 237 relative hypocenter locations converged, and the detailed hypocenter distribution beneath the Kathmandu metropolitan area was estimated (Fig. 2).

Second, we tried to estimate aftershock hypocenters for the whole focal region. The spatial distribution of the seismographic array was significantly smaller than the aftershock region. In order to evaluate the estimation errors, a nonlinear hypocenter determination procedure (Tarantola and Valette 1982, Miyamachi and Moriya 1987) was applied. Numerical hypocenter determination tests using four virtual hypocenters, the mainshock, the largest aftershock, a point $100 \mathrm{~km}$ north of the array, and a point just beneath the array, were carried out. Probabilistic densities were calculated at each grid point of $5 \mathrm{~km}$ in the horizontal and $1 \mathrm{~km}$ depth using theoretical travel times from the hypocenter to the seismic stations. Inverted hypocenter locations with confidence levels shown in Fig. 3 suggest good hypocenter estimation near the array. Earthquakes in the mainshock region, however, have horizontal errors of about $30 \mathrm{~km}$ in the NW-SE direction at the $60 \%$ confidence level and less resolution for the depth component. For the largest aftershock region, there was good determination in the longitude component, but less reliability, with $30-\mathrm{km}$ errors in the latitude component, and poor resolution in the depth determination. In the northern part of the array, the latitudinal component was well constrained, but there was less precision for the longitudinal and depth components. These results suggest that hypocenter errors depend strongly on the geometry between the array and the hypocenter.

Epicenters with $80 \%$ confidence errors for $M>4$ major events are shown in Fig. 4a. The variations in hypocenter error characteristics with epicentral distance and azimuth from the seismographic array are also well illustrated. This map suggests that our hypocenter estimation procedure may be able to conditionally clarify the characteristics of regional aftershock epicenter distributions.

\section{Results and discussion}

Hypocenters beneath the metropolitan Kathmandu region (Fig. 2) of less than $20 \mathrm{~km}$ distance from the seismographic array had errors less than $1 \mathrm{~km}$ and might indicate

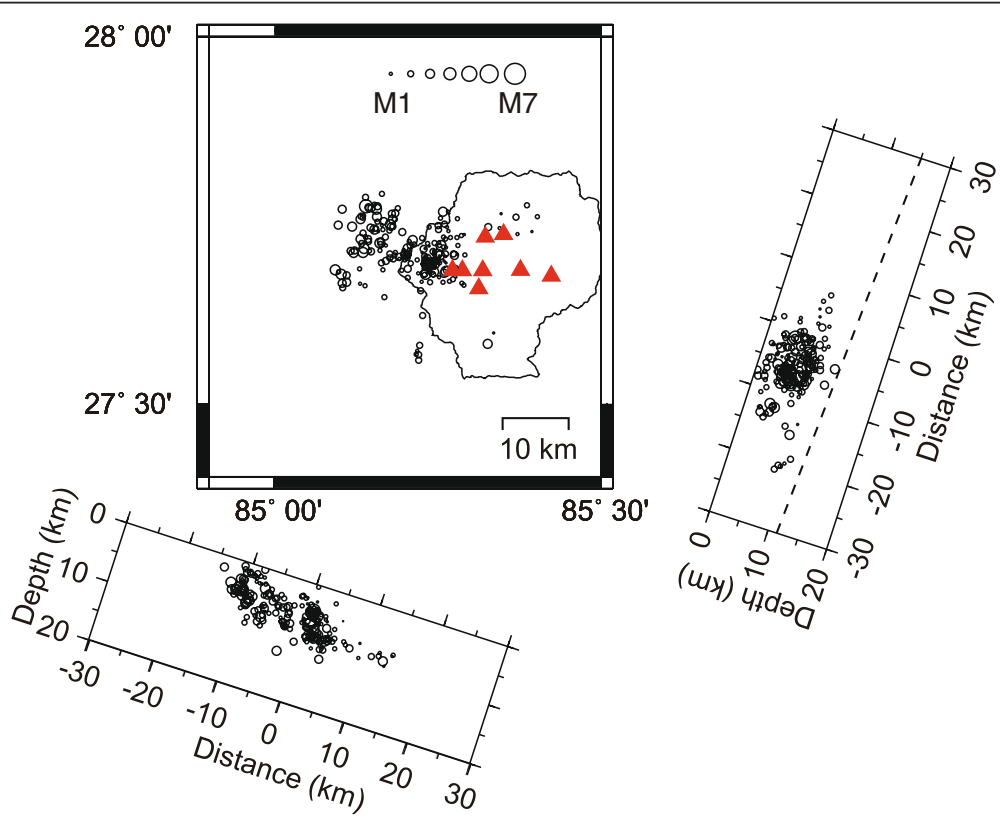

Fig. 2 Hypocenter distribution in Kathmandu region estimated from double-difference hypocenter calculation (Waldhauser and Ellsworth 2000). The cross sections are parallel and perpendicular to the strike of the Himalayan main thrust belt; a dashed line in the right section indicates the Himalayan main thrust. Triangles and solid line indicate seismographic stations and border of the Kathmandu metropolitan area, respectively 


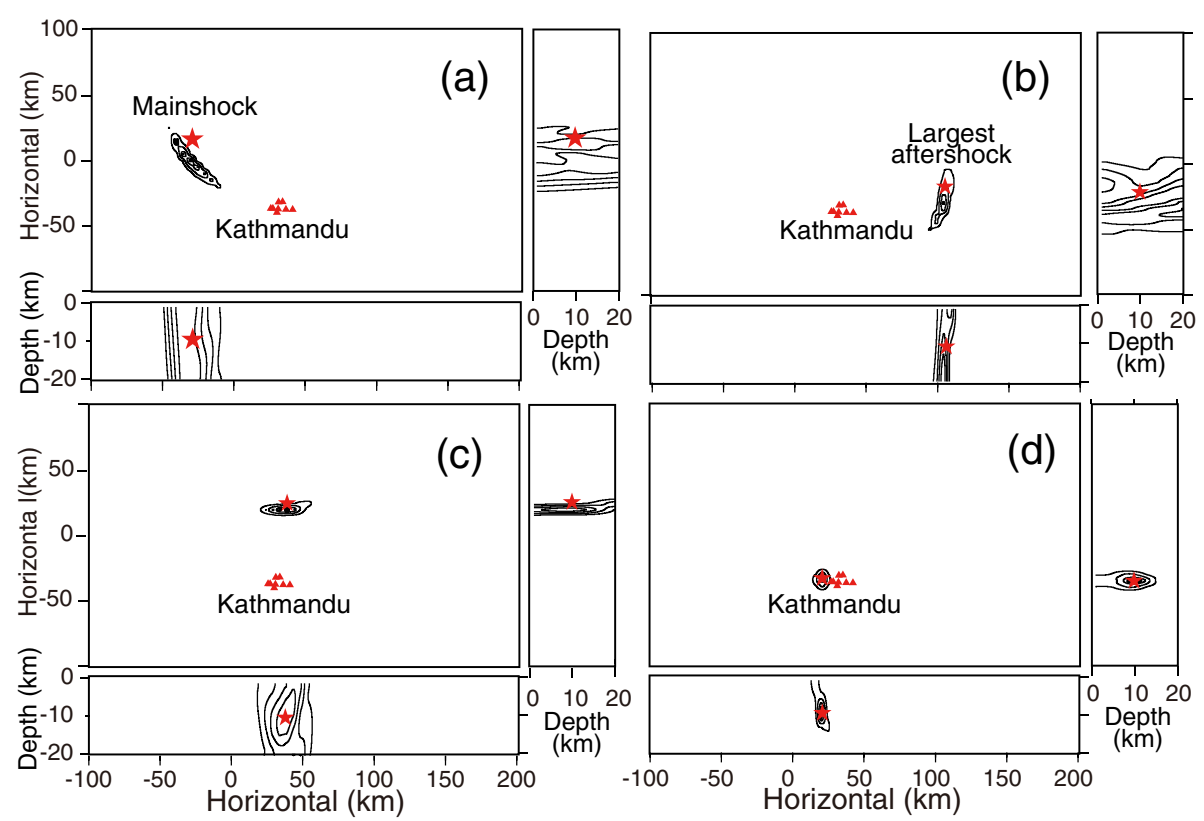

Fig. 3 Probability density distribution of hypocenter errors from nonlinear hypocenter calculation procedure. Red star indicates virtual hypocenter for test. Contour interval represents $20 \%$ confidence level for each virtual hypocenter of (a) mainshock, (b) largest aftershock, (c) region approximately $100 \mathrm{~km}$ north of array, and (d) region around array. Red triangles show seismograph stations

the characteristics of the aftershock geometry. The depths of the mainshock and main Himalayan thrust were estimated to be approximately $10 \mathrm{~km}$ beneath this region (Bollinger et al. 2014, Cattin and Avouac 2000). No clear hypocenter alignment along a shallow-dipping fault plane (which might suggest a mainshock rupture location) was identified. Most earthquakes occurred in the upper crust, at depths shallower than $10 \mathrm{~km}$, corresponding to the overriding Himalayan sequence. Delta-coulomb failure function (CFF) changes due to the mainshock were calculated using the USGS finite fault model, an effective friction coefficient of 0.45 , and Coulomb 3 software (http://earthquake.usgs.gov/earthquakes/event page/us20002926\#scientific_finitefault, Toda et al. 2005, Lin and Stein 2004). Receiver fault parameters same as the mainshock focal mechanism of USGS earthquake hazard program (strike 295, dip 11, rake $108^{\circ}$ ) were assumed (http://earthquake.usgs.gov/earthquakes/event page/us20002926\#scientific_moment-tensor:us_us_20002 926_mwc). Estimated delta-CFF values for the receiver fault of the mainshock parameters at $5-\mathrm{km}$ depth exceeded a triggering threshold of positive $0.01 \mathrm{MPa}$ (Stein, 1999). This suggests possible aftershock triggering.

A lower detectable limit of earthquake events using our strong motion array was estimated to be at least $M>4$ for the whole focal region of the mainshock from the magnitude-frequency diagram (Fig. 4c). If we take into account the error properties shown in Fig. 4a, we can claim that the major aftershocks were concentrated in the eastern part of the focal region, corresponding to the eastern edge of the relatively large coseismic slip region (e.g., Kobayashi et al. 2015, Yagi and Okuwaki 2015). Lower aftershock activity on the northwestern part of the focal region was also identified. The maximum coseismic slip there was estimated from several studies (Galetzka et al. 2015; Yagi and Okuwaki 2015; Fan and Shearer 2015; Wang and Fialko 2015). These data suggest that aftershocks occurred around the major slip region of the mainshock and were especially enhanced on the eastern edge. Similar spatial features between the major slip region and aftershock distribution have been pointed out in many previous studies (e.g., Hartzell and Heaton 1986; Beroza and Spudich 1988).

The aftershock epicenter distribution using all 1547 detected earthquakes for the period May 5-24, 2015 is shown in Fig. 4b. Although a possible inhomogeneous detectability was expected, high-activity regions in the eastern part and $30 \mathrm{~km} \mathrm{NNE}$ of the array are clearly seen. The coseismic slip and stress drop distribution estimated using multi-sensor data points to a gap in this region (Galetzka et al. 2015). Geodetic SAR fringe data (Wang and Fialko 2015) may also show leftover slip. In addition, low-frequency back-projection images of the mainshock rupture (Fan and Shearer 2015) suggest a gap. The NNE active aftershock portion may reflect heterogeneous rupture of the mainshock.

Although the aftershock hypocenter estimation was done using only data after May 5, 2015, the original four 

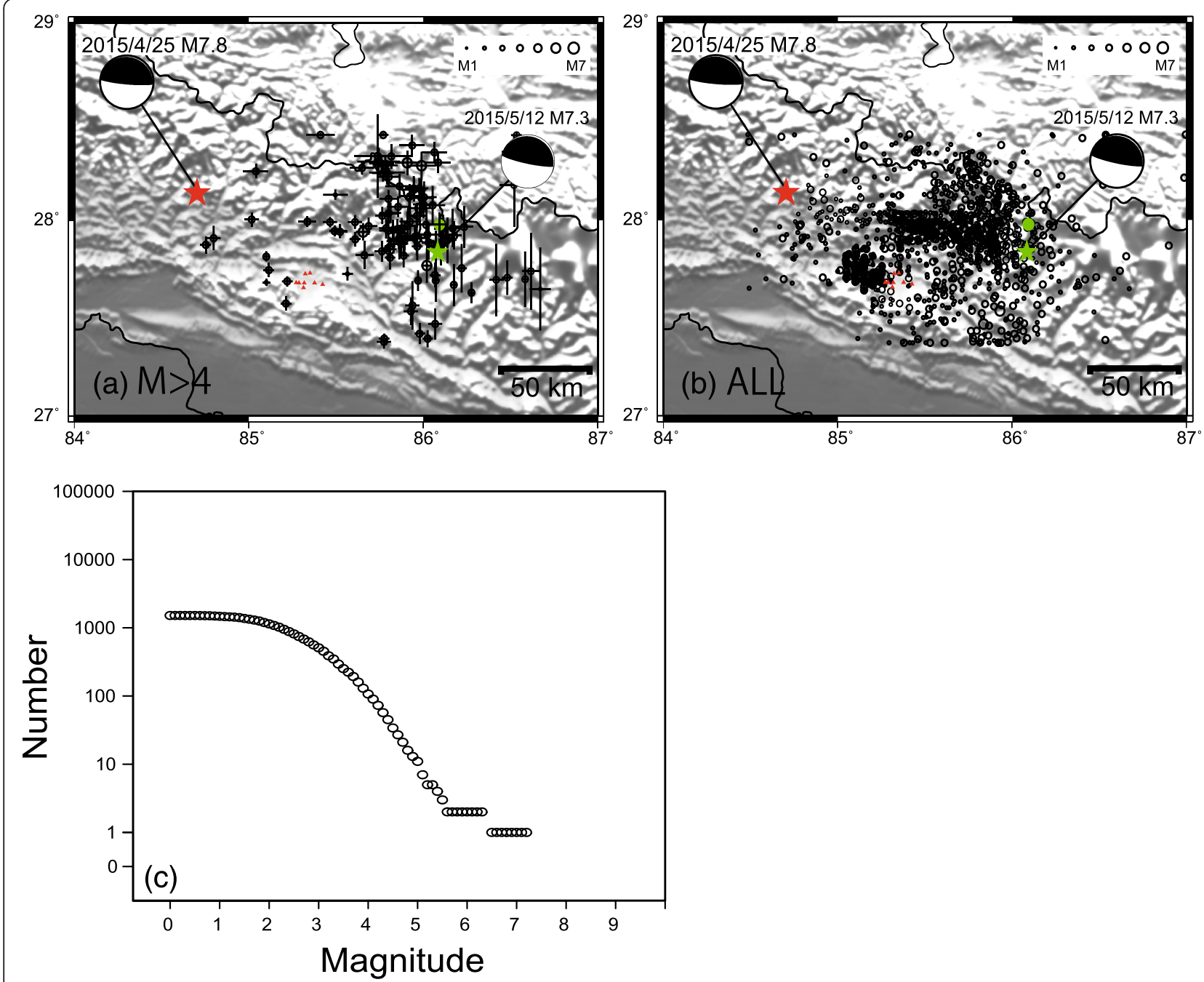

Fig. 4 Epicenter distribution estimated from nonlinear hypocenter calculation procedure for the whole focal region from May 5 to 24, 2015 of (a) M> 4 major events with error bars indicating $80 \%$ confidence level and (b) all 1547 events. Red and green stars indicate epicenters for mainshock and largest aftershock from USGS-NEIC, respectively. Green circle shows the largest aftershock epicenter estimated in this study. Triangles show seismographic stations. Focal mechanisms are from USGS-NEIC. c Magnitude-frequency relationship for all 1547 earthquakes

stations of the array had continuously recorded all the aftershock seismicity since the mainshock. The aftershock decay of the 4780 events is shown in Fig. 1b. A rapid decay of aftershock occurrence was identified, i.e., from approximately 700 earthquakes on the day of the mainshock to 350 earthquakes 2 days afterwards. The estimated $p$ value of the modified Omori law according to the XETAS analysis software (Ogata 2006; Tsuruoka and Ogata 2015) was 1.35, which also suggests rapid aftershock decay. A thermal structure study suggested possible high temperatures in the overriding Himalayan-Tibetan plateau (Herman et al. 2010). A hotter geological structure might result in rapid stress relaxation and faster aftershock decay (Mogi 1967; Kisslinger and Jones 1991).

\section{Conclusions}

The strong motion seismographic array in Kathmandu, the capital of Nepal, fully recorded the mainshock and aftershock sequence of the 2015 Gorkha, Nepal, earthquake. Hypocenter estimation and location error evaluation clarified the characteristics of aftershock activity. High-precision hypocenters beneath the array suggest that aftershocks occurred only in the overriding block of the main thrust fault. The aftershock epicentral distribution of the whole focal region clearly shows that major earthquakes were concentrated on the eastern edge of the major slip region of the mainshock. An active aftershock portion might correspond to a gap in the mainshock rupture. Rapid decay of aftershock occurrence was identified using continuous waveform data since the mainshock occurrence time. 


\section{Competing interests}

The authors declare that they have no competing interests.

\section{Authors' contributions}

$\mathrm{Ml}$ carried out the phase reading and hypocenter calculation and drafted the manuscript. NT, MS, SB, SR, and MRD designed, installed, and operated the seismographic stations. TS interpreted the hypocenter determination procedure. HT evaluated the analysis procedure, drafted the manuscript, and interpreted the aftershock characteristics from the tectonic view. All authors read and approved the final manuscript.

\section{Acknowledgements}

We thank two anonymous referees and editors for their careful reading and constructive suggestions. Prof. H. Miyamachi of Kagoshima University kindly allowed us to use his nonlinear hypocenter estimation program and discussed the results with the authors. Figures were drawn using Seis-PC (Ishikawa and Nakamura 1997) and Generic Mapping Tools (Wessel et al. 2013). Part of this study was supported by the Grant-in-Aid for Scientific Research KAKENHI 23404005, 15H01134, 15H05793, 25257204 from MEXT of Japan, JST of Japan's J-RAPID Program, Heiwa Nakajima Foundation, Obayashi Foundation, and MEXT of Japan's Earthquake and Volcano Hazards Observation and Research Program.

\section{Author details}

${ }^{1}$ Institute of Seismology and Volcanology, Hokkaido University, Kita 10, Nishi 8, Kita-ku, Sapporo, Japan. ${ }^{2}$ Faculty of Engineering, Hokkaido University, Kita 13, Nishi 8, Kita-ku, Sapporo, Japan. ${ }^{3}$ Graduate School of Engineering, Kita 13, Nishi 8, Kita-ku, Sapporo, Japan. ${ }^{4}$ Ainosato 1-4-19-12 Kita-ku, Sapporo, Japan. ${ }^{5}$ Department of Mines and Geology, Lainchour, Kathmandu, Nepal. ${ }^{6}$ Central Department of Geology, Tribhuvan University, Kirtipur, Kathmandu, Nepal.

Received: 27 October 2015 Accepted: 5 February 2016

Published: 18 February 2016

\section{References}

Beroza GC, Spudich P (1988) Linearized inversion for fault rupture behavior; application to the 1984 Morgan Hill, California, earthquake. J Geophys Res 93: 6275-6296

Bilham R, Ambraseys N (2005) Apparent Himalayan slip deficit from the summation of seismic moments for Himalayan earthquakes, 1500-2000. Curr Sci 88: $1658-1663$

Bilham R, Larson K, Freymueller J (1997) GPS measurements of present-day convergence across the Nepal Himalaya. Nature 386:61-64. doi:10.1038/ $386061 \mathrm{a0}$

Bollinger L, Sapkota SN, Tapponnier P, Klinger Y, Rizza M, Van der Woerd J, Tiwari DR, Pandy R, Bitri A, Bes de Berc S (2014) Estimating the return time of great Himalayan earthquakes in eastern Nepal: evidence from the Patu and Bardibas strands of the Main Frontal Thrust. J Geophys Res 119:7123-7163. doi:10.1002/2014JB010970

Cattin R, Avouac JP (2000) Modeling mountain building and the seismic cycle in the Himalaya of Nepal. J Geophys Res 105:13389-13407. doi:10. 1029/2000JB900032

Crosson RS (1976) Crustal structure modeling of earthquake data. 1. Simultaneous least squares estimation of hypocenters and velocity parameters. J Geophys Res 81:3036-3046

Fan W, Shearer PM (2015) Detailed rupture imaging of the 25 April $2015 \mathrm{Nepal}$ earthquake using teleseismic P waves. Geophys Res Lett 42:5744-5752. doi:10.1002/2015GL064587

Galetzka J, Melgar D, Genrich JF, Geng J, Owen S, Lindsey EO, Xu X, Bock Y, Avouac J-P, Adhikari LB, Upreti BN, Pratt-Sitaula B, Bhattarai TN, Sitaula BP, Moore A, Hudnut KW, Szeliga W, Normandeau J, Fend M, Flouzat M, Bollinger L, Shrestha P, Koirala B, Gautam U, Bhatterai M, Gupta R, Kandel T, Timsina C, Sapkota SN, Rajaure S, Maharjan N (2015) Slip pulse and resonance of the Kathmandu basin during the 2015 Gorkha earthquake, Nepal. Science 349:1091-1095. doi:10.1126/science.aac6383

Hartzell SH, Heaton TH (1986) Rupture history of the 1984 Morgan Hill, California, earthquake from the inversion of strong motion records. Bull Seismol Soc Am 76:649-674

Herman F, Copeland P, Avouac J, Bollinger L, Mahéo G, Le Fort P, Rai S, Foster D, Pêcher A, Stüwe K, Henry P (2010) Exhumation, crustal deformation, and thermal structure of the Nepal Himalaya derived from the inversion of thermochronological and thermobarometric data and modeling of the topography. J Geophys Res 115:2156-2202

Ishikawa Y. and K. Nakamura (1997) SEIS-PC for Windows95. Abs 1997 Joint Earth Planet Sci Soc P78 (in Japanese)

Kisslinger C, Jones LM (1991) Properties of aftershocks sequence in southern California. J Geophys Res 96:11947-11958

Kobayashi T, Morishita Y, Yarai H (2015) Detailed crustal deformation and fault rupture of the 2015 Gorkha earthquake, Nepal, revealed from ScanSAR-based interferograms of ALOS2. Earth Planets Space 67:201

Lave J, Avouac JP (2000) Active folding of fluvial terraces across the Siwaliks Hills, Himalayas of Central Nepal. J Geophys Res 105:5735-5770

Lin J, Stein RS (2004) Stress triggering in thrust and subduction earthquakes, and stress interaction between the southern San Andreas and nearby thrust and strike-slip fault. J Geophys Res 109:B02303

Mahesh P, Rai SS, Sivaram K, Paul A, Gupta S, Sarma R, Gaur VK (2013) Onedimensional reference velocity model and precise location of earthquake hypocenter in the Kumaon-Garhawal Himalaya. Bull Seism Soc Am 103: 328-339. doi:10.1785/0120110328

Miyamachi H, Moriya T (1987) Velocity structure and aftershock distribution of the 1982 Urakawa-oki earthquake. J Phys Earth 35:309-326

Mogi K (1967) Earthquakes and fractures. Tectonophysics 5:35-55. doi:10.1016/ 0040-1951(67)90043-1

Monsalve G, Sheehan A, Schulte-Pelkum V, Rajaure S, Pandey MR, Wu F (2006) Seismicity and one-dimensional velocity structure of the Himalayan collision zone: earthquakes in the crust and upper mantle. J Geophys Res 111:B10301. doi:10.1029/2005JB004062

Ogata Y (2006) Institute of statistic mathematics computer science monograph 33. The Institute of Statistical Mathematics, Tokyo, Japan, http://www.ism.ac. jp/ ogata/Ssg/softwares.html. Accessed 19 October 2015

Stein RS (1999) The role of stress transfer in earthquake occurrence. Nature 402: 605-609

Takai N, Shigefuji M, Bijukchhen S, Ichiyanagi M, Sasatani T (2016) Strong ground motion in the Kathmandu Valley during the 2015 Gorkha, Nepal, Earthquake. Earth Planets Space 68:10. doi:10.1186/s40623-016-0383-7

Tarantola A, Valette B (1982) Inverse problems = quest for information. J Geophys 50:159-170

Toda S, Stein RS, Richards-Dinger K, Bozkurt S (2005) Forecasting the evolution of seismicity in southern California: animations built on earthquake stress transfer. J Geophys Res 110:B05S16

Tsuruoka H. and Y. Ogata (2015) Development of seismicity analysis tool: XETAS. Program and abstract of the Seismological Society of Japan, 2015 Fall meeting:S09-P01.

Urabe T, Tsukada S (1991) Win-A workstation program for processing waveform data from microearthquake network. Prog Abstr Seismol Soc Jpn 2:331 (in Japanese)

Waldhauser F, Ellsworth WL (2000) A double-difference earthquake location algorithm: method and application to the Northern Hayward Fault, California. Bull Seism Soc Am 90:1353-1368

Wang K, Fialko Y (2015) Slip model of the 2015 Mw7.8 Gorkha (Nepal) earthquake from inversion of ALOS-2 and GPS data. Geophys Res Lett 42:7452-7458. doi:10.1002/2015GL065201

Watanabe H (1971) Determination of earthquake magnitude at regional distance in and near Japan. Jour Seism Soc Japan 24:189-200

Wessel P, Smith WHF, Scharroo R, Luis JF, Wobbe F (2013) Generic mapping tools: Improved version released. Eos Trans AGU 94:409-410

Yagi Y, Okuwaki R (2015) Integrated seismic source model of the 2015 Gorkha, Nepal, earthquake. Geophys Res Lett 42:6229-6235. doi:10.1002/2015GL064995 